\title{
Pengaruh Role Stress Terhadap Perilaku Burnout Auditor Yang Dimoderasi Oleh Emotional Quetient KAP Provinsi Bali
}

\author{
Luh Putu Devita Rahayu1 \\ Fakultas Ekonomi dan Bisnis \\ Universitas Udayana, Indonesia \\ Email: devitarahayu1712@gmail.com
}

\author{
Ni Luh Sari Widhiyani2 \\ Fakultas Ekonomi dan Bisnis \\ Universitas Udayana, Indonesia
}

\begin{abstract}
ABSTRAK
Tujuan dari penelitian ini adalah untuk membuktikan secara empiris pengaruh role stress terhadap perilaku burnout auditor dan pengaruh role stress terhadap perilaku burnout auditor yang dimoderasi oleh emotional quetient (Studi Kasus Pada KAP di Provinsi Bali). Penelitian ini dilakukan pada sembilan Kantor Akuntan Publik Provinsi Bali pada tahun 2018. Auditor sebanyak 70 orang digunakan sebagai sampel dengan menggunakan metode sampel jenuh. Pengumpulan data dilakukan dengan menyebarkan kuesioner, sebanyak 11 tidak dipergunakan karena tidak kembali dan 59 responden yang memenuhi kriteria selanjutnya di olah dengan teknik analisis moderasi regresi. Hasil analisis menunjukkan bahwa role stress memiliki pengaruh positif pada perilaku burnout auditor. Emotional quetient tidak memoderasi atau memperkuat pengaruh positif role stress pada perilaku burnout auditor.
\end{abstract}

Kata Kunci: Role Stress; Emotional Quetient; Perilaku Burnout.

The Influence Of The Role Of Stress On The Burnout Behavior Of Auditors Is Moderated By The Emotional Quetient Of The Province Of Bali

\section{ABSTRACT}

The purpose of this study was to prove the influence of the role on auditor burnout and the influence of the role on auditor burnout which was moderated by emotional quetient (Case Study in KAP in Bali Province). This research was conducted at nine Bali Provincial Public Accountants Offices in 2018 with a total of 70 auditors as a sample with a saturated sample method. Data collection was done by interviews, as many as 11 were not used because they were not returned and 59 respondents who fulfilled the next criteria were treated with the analysis regression moderation analysis technique (MRA). Based on the results of the analysis, stress roles have a positive influence on auditor burnout behavior. Emotional quotient does not moderate or influence the positive influence of the role of stress on the influence of auditor burnout.

Keywords: $\quad$ Role Stress; Emotional Quetient; Burnout Behavior.



Vol. 30 No. 2 Denpasar, Februari 2020

Hal. 334-346

Artikel Masuk: 27 September 2019

Tanggal Diterima: 1 November 2019 



\section{PENDAHULUAN}

Audit laporan keuangan perusahaan merupakan audit yang mencakup penghimpunan dan pengevaluasian bukti laporan. Audit laporan keuangan ini dilakukan oleh eksternal audit dan biasanya atas permintaan klien. Laporan keuangan perlu diaudit oleh pihak ketiga yang independen, dalam hal ini auditor eksternal. Keputusan yang dibuat oleh auditor berdasarkan atas bukti dan fakta yang ditemukan selama proses pengauditan (Shukla \& Rajeev, 2016). Pihak-pihak tersebut tentunya memiliki tujuan yang berbeda-beda, hal ini menjadi salah satu faktor penyebab auditor mengalami tingkat stress yang tinggi selama proses audit (Didik, 2008).

Auditor merupakan profesi di bidang akuntansi dengan tingkat stres yang tinggi. Auditor yang mengalami job stressakan mempunyai kecenderungan untuk mengalami penurunan kinerja dan mengurangi kualitas audit (Sergio \& Natalio, 2017). Seorang auditor memiliki potensi untuk mengalami stres karena tekanan yang didapat atas profesi tersebut sehingga menyebabkan auditor mempunyai perilaku burnout (Wiryathi et al, 2014). Pertanggung jawaban yang diberikan auditor tergantung dari tekanan dan tingkat stress yang dialami oleh auditor sehingga berpengaruh terhadap hasil laporan keuangan (Liman \& Lely, 2017).

Perilaku burnout adalah perilaku negatif atau disfungsional (distress) pada kinerja (Wiryathi et al, 2014). Pertama kali istilah burnout diutarakan oleh Fredenberger (1974) yang merupakan representasi dari sebuah sindrom stres yang dialami secara psikologis dengan respon yang negatif sebagai sebuah hasil dari tekanan dalam pekerjaan. Definisi burnout adalah sebuah sindrom psikologis yang dialami seseorang saat mengalami kelelahan emosinal dan depresi dan berakibat pada perunurunan performa kerja yang muncul pada seseorang yang bekerja dengan orang lain.

Seorang auditor dituntut untuk melaksanakan tugas yang cukup rumit sehingga memicu potensi role stress dalam diri auditor. Role stress atau tekanan peran merupakan sebuah kondisi ketika peranan setiap orang mempunyai harapan yang berbeda dengan pengaruh dari harapan orang lain, dimana harapan tersebut dapat berbenturan serta tidak jelas yang menyulitkan seseorang sehingga dapat menyebabkan peran seseorang menjadi samar-samar (Yusuf, 2014:50). Kumulatif stress dalam berbagai tingkat dan kombinasi yang dialami auditor secara terus-menerus dalam jangka panjang dapat mengakibatkan perilaku burnout. Tekanan peran (role stress) dalam pekerjaan membuat situasi auditor menjadi terperangkap sehingga hal ini merupakan salah satu penyebab stress yang dialami oleh auditor (Sandhya, 2017).

Role stress ini mempunyai akibat yang umumnya negatif seperti menurunnya kualitas hasil kerja, rendahnya loyalitas pegawai pada perusahaan, dan terjadinya perilaku burnout auditor (Sari \& Suryanawa, 2016). Didik (2008) menyatakan role stress memiliki pengaruh terhadap perilaku burnout auditor. Dwi (2017) membuktikan bahwa terdapat pengaruh positif role stress terhadap perilaku burnout auditor. Hal ini didukung oleh penelitian Platsidou \& Layla (2012) dimana dia menyatakan perilaku burnout auditor dipengaruhi oleh role stress yang dialami oleh auditor. Pernyataan yang sama dinyatakan oleh Didik (2008) bahwa tingkat role stress tinggi yang dialami auditor secara positif 
berpengaruh terhadap perilaku burnout auditor. Berbeda dengan penelitian Samuel (2010) variabel role stress secara langsung tidak berpengaruh terhadap perilaku burnout. Hal yang sama dinyatakan oleh Samae \& Omidreza (2017) perilaku burnout seorang auditor tidak dipengaruhi oleh tingkat stress yang dialaminya melainkan dari tekanan emotional dalam melakasanakan pekerjaan. Melihat dari beberapa pernyataan penelitian ini kemungkinan besar perilaku burnout auditor tidak hanya dipengaruhi oleh role stress akan tetapi pernyataan Samuel (2010) dan Samae \& Omidreza (2017) membuktikan ada pengaruh Emotional Quetient (EQ) yang menentukan sikap seorang auditor sehingga melalukan burnout.

Emotional quetient (EQ) telah diyakini menjadi ukuran standar kecerdasan. Emotional quetient (EQ) adalah kemampuan mengenali perasaan diri sendiri dan perasaan orang lain, memotivasi diri sendiri serta mengelola emosi dengan baik pada diri sendiri dan dalam hubungan dengan orang lain (Ragianda, 2017). Perlu diketahui bahwa dengan kecerdasan emosional seseorang dapat mencapai kesuksesan pada lingkungan kerja dan dapat menjaga hubungan baik dengan masyarakat sekitar lingkungan (Mimarlik et al., 2016). Beberapa penelitian seperti Avionela \& Nailul (2016) menyatakan emotional quotient memiliki pengaruh terhadap perilaku burnout auditor. Wiryathi et al., (2014) membuktikan bahwa terdapat pengaruh negatif emotional quotient terhadap perilaku burnout auditor. Sari \& Suryanawa (2016) emotional quotient secara positif mampu menurunkan perilaku burnout seseorang. Emotional quetient digunakan sebagai variabel moderasi mengingat pentingnya mencari pemecahan masalah menggunakan logika.

Hasil dari penelitian-penelitian sebelumnya mengenai role stress dan burnout menunjukkan hasil yang tidak konsisten, maka diduga ada variable lain yaitu emotional quotient. Pentingnya emotional quetient (EQ) dalam penelitian ini sebagai variabel moderasi dikarenakan emotional quetient (EQ) dikenal sebagai kemampuan untuk mengerti dan mengendalikan emosi (Akintayo, 2012). Emotional quetient (EQ) lebih banyak berhubungan dengan perasaan dan emosi seseorang. Emotional quetient (EQ) terkait dengan suatu rangkaian emosi, pengetahuan emosi dan kemampuan-kemampuan yang mempengaruhi seorang auditor dalam melaksanakan auditing sehingga mampu mengatasi role stress yang berhubungan langsung pada perilaku burnout.

Beberapa penelitian mengenai stres dan burnout pada profesi akuntan publik atau auditor yang dimoderasi oleh emotional quetient semakin banyak dilakukan. Penelitian Wiryathi et al., (2014) menyatakan emotional quetient memoderasi atau memperlemah hubungan role stress terhadap perilaku burnout auditor. Hal yang sama dinyatakan oleh Liman \& Lely (2017) dalam penelitiannya membuktikan bahwa emotional quetient secara moderasi dapat mengurangi terjadinya role stress sehingga mampu menurunkan perilaku burnout auditor. Penelitian Avionela \& Nailul (2016) juga membukitkan secara empiris perilaku burnout auditor dipengaruhi oleh role stress dapat dihindari dengan moderasi variabel emotional quetient.

Seseorang yang berprofesi sebagai auditor dituntut untuk tetap menjaga komitmennya serta meningkatkan kualitas dari jasa yang diberikan. Namun pada kondisi tertentu ketika menghadapi tuntutan yang tinggi tersebut auditor 
akan merasa tidak dapat memenuhi tuntutan tersebut sehingga hal ini dapat menimbukan stress kerja pada auditor (Samae et al., 2017). Stres dapat terjadi jika auditor sulit menginterpretasikan harapan-harapannya dalam melaksanakan audit sehingga intensitas terjadinya perilaku burnout cukup tinggi (Akintayo, 2012). Hal ini perlu adanya pengendalian emotional quetient yang berbeda-beda antara auditor yang satu dengan auditor yang lain sehingga menyebabkan setiap auditor memiliki persepsi yang baik untuk mengatasi stres kerja yang dialami (Sergio \& Natalio, 2017).

Berdasarkan latar belakang masalah yang telah dipaparkan, pokok permasalahan dalam penelitian ini adalah sebagai berikut. Apakah role stress berpengaruh pada perilaku burnout auditor. Apakah emotional quetient memoderasi pengaruh role stress pada perilaku burnout auditor.

Hasil penelitian ini dapat mendukung teori atribusi khususnya pada karakteristik yang terkait dengan mutu personal auditor yang terdapat pada tingkat role stress dan teori perubahan sikap pada dissonance theory akan berupaya mengeliminasi ketidaksesuaian yang berupa terhentinya prosedur pemeriksaan dan kesalahan yang terjadi dalam prosedur pemeriksaan dari seorang auditor. Atribusi merupakan teori yang membahas mengenai upaya-upaya seseorang dalam memahami penyebab sebuah perilaku diri sendiri dan orang lain.

Sikap merupakan penilaian yang melibatkan nalar logis dari sebuah keyakinan serta penilaian atas perasaan terhadap niatan dalam melakukan sebuah tindakan dengan orang lain pada lingkungan sekitar (Lupco et al., 2016). Perubahan atas alasan apa pun dengan keuntungan atau tidak secara umum akan bergantung pada orang lain, objeknya atau masalah yang terjadi. Perubahan sikap (attitude change) adalah bentuk spesifik dari pengendalian diri serta pengendalian sosial dan tidak tergantung pada sebuah paksaan (Mustafa et al., 2016).

Burnout adalah merupakan sebuah bentuk sindrom atas kelelahan emosional, fisik serta mental yang disebabkan oleh penderitaan stres yang intens dan berkepanjangan serta hal ini berhubungan dengan perasaan harga diri yang rendah (Baron \& Grennberg, 2003:129). Burnout adalah respon atas stres yang terjadi ditempat kerja berupa perpaduan antara sesama pekerja dengan pekerjaannya dan dialami secara terus menerus (Choi \& Young-Seok, 2015). Menurut Avionela \& Nailul (2016) ciri-ciri umum burnout dipengaruhi oleh beberapa indikator, yaitu: depersonalisasi, kelelahan emosi, rendahnya penghargaan terhadap diri sendiri.

Stres kerja akan terjadi pada kondisi apapun saat bekerja, namun hal ini dapat dikurangi agar tidak menimbulkan dampak yang negatif terutama bagi diri sendiri. Stres kerja merupakan sebuah tekanan yang dialami oleh seseorang dalam bekerja yang dapat menimbulkan tidak stabilnya emosi, memiliki perasaan yang tidak tenang, susah tidur, cemas dan tegang yang berlebihan serta senang menyendiri (Mangkunegara, 2011:28).

Kemampuan dalam menguasai bidang tertentu adalah sbeuah kecerdasan atau intelegensi. Inteligensi atau kecerdasan merpakan sebuah kekuatan atau kemampuan dalam melakukan sesuatu sehingga sangat penting bagi seorang auditor dalam mengatasi terjadinya stress yang berkepanjangan dan kejenuhan kerja (burnout). Kecerdasan merupakan kemampuan dalam 
memecahkan atau menciptakan sesuatu yang bernilai. Munzert mendefenisikan kecerdasan sebagai sikap intelektual mencakup kecepatan memberikan jawaban, penyeleasaian, dan kemampuan menyelesaikan masalah. Sehingga dapat diartikan pula bahwa kecerdasan atau Intelligensi adalah kemampuan untuk menguasai kemampuan tertentu.

Kecerdasan emosional (EQ) merupakan bentuk sikap yang mampu mengetahui tentang emosional dalam bentuk penerimaan, pemahaman dan pengelolaannya. Kemampuan untuk bertahan menghadapi tekanan serta memotivasi diri sendiri dengan pengendalian diri untuk mengatur suasana hati dan menjada agar beban yang dirasakan tidak menjadi stress atau tekanan yang berlebihan merupakan bentuk dari kecerdasan emosional. Terdapat beberapa indikator-indikator yang mempengaruhi emotional auotient (EQ) diantaranya yaitu: Kesadaran diri, pengaturan diri, motivasi, empati dan keterampilan Sosial (Wiryathi et al., 2014).

Menurut Robbins \& Judge (2011:97), tekanan kerja (job stress) yaitu pandangan mengenai disfungsi individu yang disebabkan oleh lingkungan di dalam tempat kerja yang akan memiliki pengaruh positif terhadap perilaku burnout. Role stress yang dirasakan dari tekanan kerja merupakan multidimensional yang pada dasarnya yaitu tekanan beban kerja, tekanan waktu, tekanan kinerja, konflik peran, dan lain sebagainya yang memiliki hubungan positif dengan perilaku burnout auditor. Beberapa penelitian dimana Didik (2008), Ermayanti (2017), Platsidou \& Layla (2012), dan Balogun (2014) menyatakan hal yang sama yaitu role stress memiliki pengaruh terhadap perilaku burnout auditor. Dari penjelasan di atas, maka hipotesis yang dapat dirumuskan adalah sebagai berikut:

$\mathrm{H}_{1}$ : Role stress berpengaruh positif pada perilaku burnout auditor.

Teori atribusi menjelaskan konsep emotional quotient mampu memberikan pengaruh positif untuk menurunkan tingkat turnover intention pada auditor (Sergio \& Natalio, 2017). Pengendalian diri berupa kemampuan untuk memahami diri sendiri dengan baik yang kemudian dapat menghindari terjadinya roll stress. Empati merupakan kemampuan memahami orang lain sehingga tidak terjadi tindakan yang merugikan orang lain untuk berperilaku burnout (Wiryathi et al., 2014). Beberapa penelitian seperti Wiryathi et al., (2014), Liman \& Lely (2017), Avionela \& Nailul (2016), serta Samae \& Omidreza, (2017) menyatakan hal yang sama yaitu emotional quetient memoderasi atau memperlemah hubungan role stress terhadap perilaku burnout auditor. Dari penjelasan di atas, maka hipotesis yang dapat dirumuskan adalah sebagai berikut.

$\mathrm{H}_{2}$ : Emotional quotient memoderasi pengaruh role stressterhadap perilaku burnout auditor.

\section{METODE PENELITIAN}

Penelitian ini dilakukan pada Kantor Akuntan Publik yang berada di Bali serta terdaftar pada Institut Akuntan Publik Indonesia. Jumlah Kantor Akuntan Publik yang terdaftar pada Institut Akuntan Publik Indonesia pada tahun 2018 disajikan pada Tabel. 1. 
Tabel. 1 Daftar Kantor Akuntan Publik di Bali

\begin{tabular}{|c|c|c|}
\hline No. & $\begin{array}{l}\text { Nama Kantor Akuntan } \\
\text { Publik }\end{array}$ & Publik \\
\hline 1. & KAP I Wayan Ramantha & $\begin{array}{l}\text { No. IA Lt. } 3 \text { Denpasar, Bali. Telp: } \\
643\end{array}$ \\
\hline 2. & $\begin{array}{l}\text { KAP Johan Mal } \\
\text { Mustika \& Rekan (Cab) }\end{array}$ & $\begin{array}{l}\text { Jl. Muding Indah 1/5, Kerobokan, Kuta Utara, } \\
\text { Badung, Bali. Telp: (0361) } 434884\end{array}$ \\
\hline 3. & KAP K. Gunarsa & sari Gg. II No 5. Telp: (0361) \\
\hline 4. & $\begin{array}{l}\text { KAP Drs. Ketut Budiartha, } \\
\text { MSi }\end{array}$ & $\begin{array}{l}\text { Perum Padang Pesona Graha Adhi,Blok A6, Jl. } \\
\text { Gunung Agung Denpasar, Bali. Telp: (0361) } \\
8849168\end{array}$ \\
\hline 5. & $\begin{array}{l}\text { KAP Drs. Sri Mc } \\
\text { Djogosarkoro \& Rekan }\end{array}$ & $\begin{array}{l}\text { Jl. Gunug Muria Blok VE No.4, Monang } \\
\text { Maning, Denpasar, Bali. Telp: (0361) 480033, } \\
480032,482422\end{array}$ \\
\hline 6. & $\begin{array}{l}\text { KAP Drs. } \\
\text { Sunasdyana }\end{array}$ & $\begin{array}{l}\text { Jl. Pura Demak I Gang Buntu No. 89, Denpasar, } \\
\text { Bali. Telp: (0361) 7223329, } 8518989\end{array}$ \\
\hline 7. & $\begin{array}{l}\text { KAP Drs. Ketut Mulia } \\
\text { R.M \& Rekan }\end{array}$ & adi No. 25 Denpasar, Bali \\
\hline 8. & KAP Arnaya \& Darmayasa & g Hill No. 1 \\
\hline & KAP Budhananda Munidewi & Jl. Tukad Irawadi N. 18 A, Lantai $2 \& 3$ \\
\hline
\end{tabular}
Sumber: Directori IAPI, 2019.

Emotional quetient memoderasi pengaruh role stress terhadap perilaku burnout auditor merupakan objek dalam penelitian ini. Seluruh auditor yang bekerja pada Kantor Akuntan Publik di Bali berjumlah sebanyak 70 orang merupakan populasi dalam penelitian ini. Sebanyak 70 orang merupakan jumlah sampel yang digunakan pada penelitian ini yaitu keseluruhan auditor yang bekerja di Kantor Akuntan Publik di Bali dengan menggunakan metode sensus.

Data kuantitatif pada penelitian ini adalah jumlah auditor yang bekerja di kantor akuntan publik dan hasil kuisioner yang merupakan jawaban responden yang terukur dengan skala Linkert. Data kualitatif pada penelitian ini adalah nama kantor akuntan yang terdaftar di Directory Kantor Akuntan Publik wilayah Bali, gambaran umum kantor akuntan publik, serta struktur organisasi kantor akuntan publik. Data primer pada penelitian ini adalah jawaban dari responden dalam kuesioner yang berhubungan dengan penelitian. Data sekunder dalam penelitian ini yaitu sekumpulan data berupa daftar Kantor Akuntan Publik (KAP) yang berada di Bali.

Teknik kuesioner digunakan sebagai metode pengumpulan data yang dilakukan dengan cara memberi seperangkat pertanyaan atau pernyataan tertulis kepada responden untuk dijawab (Sugiyono, 2017:162), observasi dengan cara mengadakan pengamatan langsung ke perusahaan terhadap obyek yang diteliti, seperti aktivitas auditor, wawancara dengan bertanya langsung kepada auditor, data yang diperoleh dengan teknik wawancara berupa data jumlah auditor yang bekerja pada Kantor Akuntan Publik di Bali.

Penelitian ini menggunakan teknik analisis data yang dilakukan secara kuantitatif dengan menggunakan data primer yang kemudian data akan diolah untuk dapat dilakukan analisis. Analisis data dilakukan secara kuantitatif 
dengan menerapkan landasan teori dengan harapan akan mendapatkan kesimpulan yang berbobot ilmiah. Teknik perhitungan dan analisis data menggunakan Moderating Regression Analysis yang dinyatakan dalam bentuk regresi berganda dengan persamaan mirip regressi polynomial yang menggambarkan pengaruh nonlinier Ghozali (2016:47) dan dinyatakan dalam bentuk model persamaan berikut.

$$
Y=\alpha+\beta_{1} X+\beta_{2}(X M)
$$

Keterangan:

$\mathrm{Y}=$ perilaku burnout auditor

$\mathrm{a} \quad=$ konstanta

$\beta_{1}, \beta_{2}=$ koefisien regresi moderasi masing-masing variabel independen

$\mathrm{X} \quad=$ role stress

$\mathrm{M} \quad=$ emotional quotient

Selanjutnya dilakukan analisis hipotesis berupa uji koefisien determinasi $\left(\mathrm{R}^{2}\right)$, uji kelayakan model (Uji F) dan uji hipotesis (Uji t).

\section{HASIL DAN PEMBAHASAN}

Penelitian ini dilakukan untuk mengetahui pengaruh role stress terhadap perilaku burnout auditor yang dimoderasi oleh emotional quotient. Pengumpulan data dilakukan dengan menyebar kuesioner ke sembilan kantorAkuntan Publik di Bali. Ringkasan pengiriman dan pengembalian kuesioner disajikan pada Tabel. 2.

\section{Tabel. 2 Rincian Pengiriman dan Pengembalian Kuesioner}

\begin{tabular}{lll}
\hline Kuesioner & Jumlah & Persentase $(\%)$ \\
\hline Kuesioner yang disebar & 70 & 100 \\
Kuesioner yang tidak kembali & 11 & 15,7 \\
Kuesioner yang kembali & 59 & 84,3 \\
Kuesioner yang digunakan & 59 & 84,3 \\
Tingkat pengembalian kuisioner & $59 / 70 \times 100 \%=$ & 84,3 \\
\hline
\end{tabular}

Sumber: Data Penelitian, 2018

Tabel. 2 menunjukan bahwa kuesioner yang disebar ke responden sebanyak 70 kuesioner, yang kembali sebanyak 59 kuesioner, sedangkan yang tidak dikembalikan sebanyak 11 kuesioner. Semua kuesioner yang kembalilengkap pengisiannya dan memenuhi ketentuan, kemudian dianalisis.

Tabel. 3 Karakteristik Responden

\begin{tabular}{llll}
\hline Karakteristik & Klasifikasi & Jumlah & Persentase \\
Jenis Kelamin & Laki-Laki & 41 & 69,5 \\
& Perempuan & 18 & 30,5 \\
Total & & 59 & 100 \\
Pendidikan Terakhir & Diploma 3 & 5 & 8,5 \\
& S1 & 39 & 66,1 \\
& S2 & 15 & 25,4 \\
Total & & 59 & 100 \\
Lama bergabung dalam tim Audit & Kurang dari 5 tahun & 15 & 25,4 \\
& $>5$ s/d 10 tahun & 44 & 74,6 \\
Total & & 59 & 100 \\
\hline
\end{tabular}

Sumber: Data Penelitian, 2018. 
Berdasarkan Tabel. 3 dapat diketahui proporsi auditor laki-laki dan perempuan berdasarkan jenis kelamin yaitu jumlah auditor laki-laki adalah 41 orang responden 69,5 persen dan auditor perempuan yaitu 18 orang responden 30,5 persen. Hal ini berarti responden pada Kantor KAP di dominasi oleh auditor laki-laki. Responden yang memiliki tingkat pendidikan Diploma sebanyak 5 orang 8,5 persen, S1 sebanyak 39 orang atau 66,1 persen dan S2 sebanyak 15 orang atau sebanyak 25,4 persen. Ini menandakan rata-rata tingkat pendidikan auditor adalah S.1, yang memiliki arti semakin baik tingkat pendidikan seorang auditor menunjukkan tingkat kinerja yang semakin baik pula dengan kualitas hasil audit yang lebih baik.Responden yang tergabung dalam tim audit kurang dari lima tahun adalah 15 orang atau 25,4 persen. Responden yang tergabung dalam tim audit lebih dari lima tahun adalah 44 orang 74,6 persen. Seluruh responden pada penlitian ini sudah pernah tergabung dalam tim audit pada Kantor KAP sehingga responden dalam penelitian ini layak untuk digunakan dan menunjukkan data yang valid.

Tabel. 4 Hasil Uji Validitas dan Reliabilitas

\begin{tabular}{|c|c|c|c|c|c|}
\hline Variabel & $\begin{array}{l}\text { Kode } \\
\text { Instrumen }\end{array}$ & $\begin{array}{l}\text { Pearson } \\
\text { Correlation }\end{array}$ & Keterangan & $\begin{array}{l}\text { Cronbach's } \\
\text { Alpha }\end{array}$ & Keterangan \\
\hline \multirow{5}{*}{$\begin{array}{l}\text { Emotional } \\
\text { Quetient (M) }\end{array}$} & $\mathrm{M}_{1}$ & 0,558 & Valid & \multirow{5}{*}{0,787} & \multirow{5}{*}{ Reliabel } \\
\hline & $\mathrm{M}_{2}$ & 0,744 & Valid & & \\
\hline & $\mathrm{M}_{3}$ & 0,847 & Valid & & \\
\hline & $\mathrm{M}_{4}$ & 0,715 & Valid & & \\
\hline & $\mathrm{M}_{5}$ & 0,815 & Valid & & \\
\hline \multirow{4}{*}{$\begin{array}{l}\text { Role } \\
(\mathrm{X})\end{array}$} & $X_{1.1}$ & 0,786 & Valid & \multirow{4}{*}{0,682} & \multirow{4}{*}{ Reliabel } \\
\hline & $\mathrm{X}_{1.2}$ & 0,779 & Valid & & \\
\hline & $X_{1.3}$ & 0,670 & Valid & & \\
\hline & $\mathrm{X}_{1.4}$ & 0,651 & Valid & & \\
\hline \multirow{3}{*}{ Burnout $(\mathrm{Y})$} & $\mathrm{Y}_{.1}$ & 0,843 & Valid & \multirow{3}{*}{0,757} & \multirow{3}{*}{ Reliabel } \\
\hline & $\mathrm{Y}_{.2}$ & 0,735 & Valid & & \\
\hline & $\mathrm{Y}_{.3}$ & 0,879 & Valid & & \\
\hline
\end{tabular}

Sumber: Data Penelitian, 2018.

Tabel. 4 menunjukkan bahwa seluruh indikator pernyataan dalam variabel kualitas audit, komitmen profesional dan reward, memiliki nilai pearson correlation yang lebih besar dari 0,30. Dengan demikian dapat disimpulkan bahwa seluruh indikator telah memenuhi syarat uji validitas.Seluruh instrumen penelitian yang digunakan yaitu kualitas audit, independensi, keahlian audit, pengalaman dan besaran fee auditmemiliki koefisien Cronbach's Alphalebih besar dari 0,60 sehingga instrumen yang digunakan dalam penelitian ini dinyatakan reliabel.

Tabel. 5 Hasil Statistik Deskriptif

\begin{tabular}{llllll}
\hline Variabel & N & Min. & Max. & Mean & $\begin{array}{l}\text { Std. } \\
\text { Deviasi }\end{array}$ \\
\hline Role Stress (X) & 59 & 10 & 20 & 14,97 & 2,539 \\
Emotional Quetient $(\mathrm{M})$ & 59 & 12 & 25 & 19,41 & 3,389 \\
Burnout $(\mathrm{Y})$ & 59 & 8 & 15 & 13,39 & 1,820 \\
\hline
\end{tabular}

Sumber: Data Penelitian, 2018

Berdasarkan Tabel. 5 menunjukkan bahwa deskriptif variabel role stress (X) dengan nilai minimum sebesar 10, nilai maksimum sebesar 20, nilai mean 
sebesar 14,97 serta standar deviasi sebesar 2,539. Ini menunjukkan bahwa terjadi perbedaan nilai role stressyang diteliti terhadap nilai rata-ratanya sebesar 2,539.

Variabel emotional quetient (M) dengan nilai minimum sebesar 12, nilai maksimum sebesar 25, nilai mean sebesar 19,41, dan standar deviasi sebesar 3,389. Ini menunjukkan bahwa terjadi perbedaan nilai emotional quetient yang diteliti terhadap nilai rata-ratanya sebesar 3,389.

Variabel burnout $(\mathrm{Y})$ dengan nilai minimum sebesar 8, nilai maksimum sebesar 15, mean sebesar 13,39, dan standar deviasi sebesar 1,820. Ini menunjukkan bahwa terjadi perbedaan nilai burnout yang diteliti terhadap nilai rata-ratanya sebesar 1,820 .

Tabel. 6 Hasil Uji Asumsi Klasik

\begin{tabular}{|c|c|c|c|c|}
\hline \multirow{2}{*}{$\begin{array}{l}\text { Parameter } \\
\text { Diuji }\end{array}$} & $\begin{array}{l}\text { Uji } \\
\text { Normalitas }\end{array}$ & Uji Heteroskedastisitas & \multicolumn{2}{|c|}{ Uji Multikolinearitas } \\
\hline & $\begin{array}{l}\text { Asymp. Sig. } \\
\text { (2-tailed) }\end{array}$ & Sig. & Tolerance & VIF \\
\hline $\begin{array}{l}\text { Unstandarized } \\
\text { Residual }\end{array}$ & 0,480 & & & \\
\hline Role Stress (X) & & 0,175 & 0,130 & 3,675 \\
\hline $\begin{array}{l}\text { Emotional Quetient } \\
\text { (M) }\end{array}$ & & 0,196 & 0,126 & 3,187 \\
\hline
\end{tabular}

Sumber: Data Penelitian, 2018

Berdasarkan tabel. 6 dapat dilihat nilai asymp.sig. yang dimiliki lebih besar dari alpha 0,05 hal ini menunjukkan bahwa model regresi yang digunakan dalam penelitian ini berdistribusi normal. masing-masing variabel role stress dan emotional quetient lebih besar dari 0,05 yang berarti variabel tersebut bebas heteroskedastisitas. Nilai tolerence masing-masing variabel lebih besar dari 0,1 dan nilai VIF lebih kecil dari 10, hal ini mengindikasikan bahwa dalam model regresi tidak terjadi multikolinearitas.

Tabel. 7 Hasil Pelaporan Analisis MRA

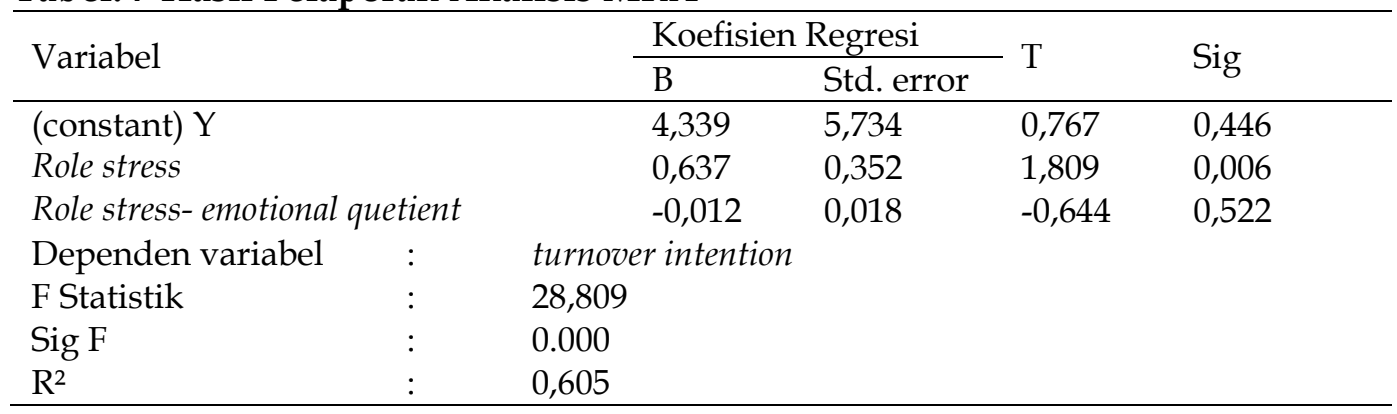

Sumber : Data Penelitian, 2018

Persamaan regresi pada Tabel. 7 dapat dijelaskan untuk setiap variabel hal-hal sebagai berikut:

$$
\mathrm{Y}=4,339+0,637 \mathrm{X}-0,012|\mathrm{ZM}-\mathrm{ZX}|
$$

Nilai konstanta yang diperoleh yaitu 4,339 yang berarti jika terjadi nilai dari variabel bebas yaitu role stress dan emotional quetient sama dengan nol atau bersifat konstan, maka kualitas audit tidak mengalami penurunan. Nilai Koefisien $\beta_{1}$ yang diperoleh yaitu 0,637 memiliki tanda positif yang menunjukan bahwa apabila role stress meningkatkan maka perilaku burnout auditor juga akan cenderung meningkat. Nilai Koefisien $\beta_{2}$ yang diperoleh sebesar -0,012memiliki 
tanda negatif yang menunjukan bahwa interaksi antara variabel emotional quetient dengan role stress bersifat negatif. Hal ini menunjukkan bahwa interaksi emotional quetienttidak memperkuat pengaruh antara role stress terhadap perilaku burnout auditor.

Pada Tabel. 7 terdapat hasil uji statistik $\mathrm{F}$ yang menunjukkan nilai siginifikansi sebesar 0,000 lebih kecil dari tingkat a $(0,05)$. Hal ini mengandung arti bahwa variabel emotional quetient dan role stress secara bersamaan berpengaruh signifikan terhadap perilaku burnout auditor pada Kantor Akuntan Publik di Bali. Berdasarkan hal tersebut dapat disimpulkan bahwa model yang digunakan dalam penelitian ini layak untuk digunakan.

Berdasarkan Tabel. 7 menunjukkan nilai $\mathrm{t}$ hitung variabel role stress adalah sebesar 1,809 dengan tingkat signifikansi sebesar 0,06 yang berarti bahwa role stress berpengaruh positif dan signifikan terhadap perilaku burnout auditor pada Kantor Akuntan Publik di Bali. Tingkat role stressyang semakin tinggi pada seorang auditor mengindikasikan perilaku burnout auditor yang semakin meningkat pula.

Diketahui bahwa nilai nilai t hitung $|\mathrm{ZM}-\mathrm{ZX}|$ atau variabel emotional quetient dan role stress sebesar -0,644 dengan tingkat signifikansi sebesar 0,522 lebih besar dibandingkan dengan taraf nyata a $(0,05)$. Berdasarkan hal tersebut dapat disimpulkan bahwa emotional quetienttidakberperan sebagai variabel yang memoderasi hubungan antara role stress dengan perilaku burnout auditor pada Kantor Akuntan Publik di Bali.

Berdasarkan Tabel. 7 dapat dilihat bahwa nilai adjusted $\mathrm{R}$ square model adalah 0,605 atau $60,5 \%$ yang mengandung arti bahwa $60,5 \%$ variasi atau perubahan perilaku burnout auditor dapat terjelaskan oleh variasi variabel dalam model tersebut yaitu emotional quetient dan role stress. sedangkan sisanya sebesar 39,5 persen dijelaskan oleh faktor lain yang tidak dimasukkan ke dalam model.

Berdasarkan hasil perhitungan yang menunjukan bahwa variabel role stress berpengaruh positif dan signifikan pada perilaku burnout auditor. Pengaruh yang positif menunjukkan bahwa tingkat role stress yang semakin tinggi yang dialami auditordalam bekerja akan meningkatkan terjadinya perilaku burnout auditor. Sebaliknya, semakin rendah tingkat role stress yang dialami auditor dalam bekerja, maka akan semakin rendah pula perilaku burnout auditor. Attitude change theory merupakan model yang sering digunakan dalam menjelaskan hubungan antara role stress dan burnout dimana tingkat stress yang dialami oleh seorang auditor yang sudah bekerja cukup lama akan meningkatkan perilaku burnout pada auditor. Tekanan kerja merupakan multidimensional yang pada dasarnya akan menyebabkan tekanan, kejenuhan dan bosan terhadap pekerjaan sehingga memiliki perilaku burnout.

Hasil penelitian ini didukung oleh penelitian Didik (2008) yang menyatakan bahwa variabelrole stress memiliki pengaruh terhadap perilaku burnout auditor. Hal yang sama dibuktikan oleh Dwi (2017) dalam penelitiannya menyatakan bahwa terdapat pengaruh positif role stress terhadap perilaku burnout auditor. Platsidou \& Layla (2012) dalam penelitiannya membuktikan hal yang sama dimana perilaku burnout auditor dipengaruhi oleh role stress yang dialami oleh auditor. Dipertegas oleh penelitian Wiryathi et al., (2014) 
menyatakan hal yang samarole stress secara positif berpengaruh terhadap perilaku burnout auditor.

Berdasarkan hasil perhitungan yang menunjukan bahwa variabel emotional quetient tidak memoderasi atau tidak memperkaut pengaruh positif role stress pada perilaku burnout auditor. Teori Attitude change memberikan pemahaman bahwa emotional quotient berhubungan dengan kemampuan mengontrol peristiwa dalam pengendalian diri dan empati. Pengendalian diri berupa kemampuan untuk memahami diri sendiri dengan baik yang kemudian dapat menghindari terjadinya roll stress. Empati merupakan kemampuan memahami orang lain sehingga tidak terjadi tindakan yang merugikan orang lain untuk berperilaku burnout (Wiryathi et al., 2014).

Hasil penelitian ini didukung oleh penelitian Wiryathi et al., (2014) menyatakan emotional quetient memoderasi atau memperlemah hubungan role stress terhadap perilaku burnout auditor. Liman \& Lely (2017) membuktikan bahwa emotional quetient secara moderasi dapat mengurangi terjadinya role stress sehingga mampu menurunkan perilaku burnout auditor. Avionela \& Nailul (2016) perilaku burnout auditor yang dipengaruhi oleh role stress dapat dihindari dengan moderasi variabel emotional quetient. Samae et al., (2017) menyatakan hal yang sama pengaruh role stress secara positif terhadap perilaku burnout auditor secara moderasi dapat diperlemah oleh emotional quetient.

\section{SIMPULAN}

Berdasarkan hasil penelitian yang telah dibahas sebelumnya, maka kesimpulan yang didapat adalah: Role stress berpengaruh positif dan signifikan pada perilaku burnout auditor. Hal ini menunjukkan bahwa tingkat role stress yang dialami seorang auditor akan meningkatkanperilaku burnout auditor. Emotional quetient tidakmemoderasi pengaruh positif role stress padaperilaku burnout auditor. Hal tersebut menunjukkan bahwa semakin baik emotional quetient seorang auditormaka semakin menurunnya tingkat role stress seorang auditor dalam melaksanakan audit sehingga menurunkan perilaku burnout auditor.

Saran yang dapat diajukan untuk menekan terjadinya perilaku burnout auditor harus menerapkan sikap emotional quetient dengan pemahaman yang rasional, emosi yang stabil dan sikap yang tenang, akan memberikan peran positif dalam menurunkan tingkat stress dalam bekerja yang tentunya akan menurunkan perilaku burnout auditor. Role stress yang dialami auditor memiliki peran positif untuk meningkatkan perilaku burnout auditor. Role stress dapat dikatakan sebagai tekanan kerja yang berat, sehingga perlu melakukan perubahan dengan menerapkan sikap emotional quetient yang mengajarkan seorang auditor untuk bekerja secara ikhlas dan terlepas dari perilaku burnout.Bagi peneliti selanjutnya diharapkan untuk menggunakan variabel lain seperti role ambiguty, ethical sensitivity, dengan meneliti pada lokasi yang berbeda seperti pada perusahaan jas perbankan, perusahaan milik pemerintah atau perusahaan lainnya yaitu dengan meneliti auditor internal perusahan.

\section{REFERENSI}

Akintayo, D. (2012). Influence Of Emotional Intelligence On Work-Family Role Conflict Management And Reduction In Withdrawal Intentions Of 
Workers In Private Organizations. International Business \& Economics Research Journal, 9(12), 131-140.

Avionela, F., dan Nailul, F. (2016). Hubungan Antara Kecerdasan Emosi dengan Burnout pada Guru Bersertifikat di SMA Negeri Kecamatan Bojonegoro. Jurnal Empati, 5(4), 687-693.

Balogun, A. G. (2014). Job burnout among working mothers in Nigeria postconsolidation banks: Effects of work-family conflict and job stress. International Journal of Research Studies in Psychology, 3(5), 27-36.

Baron, R. A., and Grennberg, J. (2003). Behavior in organizations: Understanding and managing the human side of work (8th ed.). Upper Saddle River: Pearson Education.

Bastian, Indra. (2001). Audit Sektor Publik. Jakarta: Visi Global Media.

Casmini. (2007). Emotional Parenting. Yogyakarta: Pilar Medika.

Choi, Y.-G., and Young-Seok, K. (2015). The Influence of Emotional Labor on Burnout: Centered on the Stress Coping Strategy and Moderating Effect of Social Support. International Journal of Social Science and Humanity, 5(7), 583-588.

Didik. (2008). Pengaruh Role Stress terhadap Perilaku Disfungsional Internal Auditor. Jurnal Dimensia, 5(1), 41-104.

Duygusal, M. Ö., and Tükenmişlik, D. A. (2016). The Relationship Between Emotional Intelligence and Burnout Levels Among Architecture Students. International Journal of Business \& Economics Research, 4(1), 491-501.

Dwi, E. (2017). Pengaruh Emotional Quotient, Pengalaman Auditor Dan Akuntabilitas Terhadap Kualitas Audit. Jurnal Ekonomi Dan Kewirausahaan, 12(2), 178-190.

Eka, Mustiasri. (2016). Anteseden dan Konsekuensi Burnout Pada Auditor: Pengembangan Terhadap Role Stress Model. Jurnal Simposium Nasional Akuntansi, 2(1), 1-27.

Ghozali, I. (2016). Aplikasi Analisis Multivariete dengan Program IBM SPSS 23 (8th ed.). Semarang: Undip.

Kreitner dan Kinicki. (2008). Perilaku Organisasi. Jakarta: Selemba Empat.

Liman, D. S., dan Lely, A. M. (2017). Kecerdasan Emosional sebagai Pemoderasi Pengaruh Kompetensi dan Independensi Auditor terhadap Kinerja Auditor. Jurnal Ekonomi Dan Bisnis Udayana, 21(1), 562-587.

Lupco, K., Marija, K. D., and Dragan, R. (2016). The Influence of The Emotional Intelegence in Protection of the Menta; Health in Conditions of A Psychosocial Stress. International Journal of Cognitive Research in Science, Engineering and Education, 4(1), 17-21.

Mangkunegara, A. P. (2011). Manajemen Sumber Daya Manusia Perusahaan. Bandung: PT. Remaja Rosdakarya.

Mohammadyfar, M. A., Mahmmod S. K., and Bahman, K. T. (2009). The Effect of Emotional Intelligence and Job Burnout on Mental and Physical Health. Journal of the Indian AcDidikmy of Applied Psychology, 35(2), 219-226.

Mulyadi. (2011). Auditing (6th ed.). Jakarta: Salemba Empat. 
Mustafa, M., Santos, A., and Chern, G. T. (2016). Emotional intelligence as a moderator in the emotional labour-burnout relationship: evidence from Malaysian HR professionals. International Journal of Work Organisation and Emotion, 7(2), 143-164.

Myoung-Jin, Kwon., and Young-Hee, Kim. (2016). Burnout, Emotional Labor and Emotional Intelligence of Psychological Nurses. International Journal of Bio-Science and Bio-Technology, 8(2), 245-254.

Nata, Wirawan. (2002). Statistic 2 (Statistik Inferensial). Edisi pertama. Denpasar: Keraras Emas.

Platsidou, M., and Layla, S. (2012). The role of emotional intelligence in predicting burnout and job satisfaction of Greek lawyers. International Journal of Business \& Economics Research, 1(1), 13-22.

Ragianda, H. (2017). Pengaruh Spiritual Quotient, Emotional Quotient, dan Adversity Quotient terhadap Kualitas Audit (KAP di Jakarta). Jurnal Ekonomi Dan Kewirausahaan, 4(2), 158-169.

Riduwan dan Sunarto. (2007). Pengantar Statistika Untuk Penelitian Pendidikan, Sosial, Ekonomi, dan Bisnis. Bandung: Alfabeta.

Robbins, S. P., and Judge, T. A. (2011). Perilaku Organisasi (12th ed.). Jakarta: Salemba Empat.

Samae, S. E., Yahya, K., and Omidreza, H. (2017). The Effect of Emotional Intelligence and Job Stress on Burnout: A Structural Equation Model among Hospital Nurses. International Journal of Occupational Hygiene, $14(2), 52-59$.

Samuel, S. (2010). Accupational Stress and Well-Being" Emotional Intellegence, Selfefficacy. Coping, Negative Affectivitiy and Social Support as Moderators. Journal of International Social Research, 3(12), 387-398.

Sandhya, A. (2017). Role of emotional intelligence as a buffer effect in stress management of newly recruited employees. International Journal of Applied Sciences and Management, 2(2), 269-282.

Sari, E. R., dan Suryanawa, I. K. (2016). Pengaruh Konflik Peran, Ketidakjelasan Peran, dan Kelebihan Peran terhadap Kinerja Auditor dengan Tekanan Waktu sebagai variabel Moderasi. Jurnal Ekonomi Dan Bisnis Udayana, 15(2), 1392-1421.

Sergio, M.-L., and Natalio, E. (2017). Contributions of Work-Related Stress and Emotional Intelligence to Teacher Engagement: Additive and Interactive Effects. Journal of International Social Research, 1(4), 1-15.

Shukla, A., and Rajeev, S. (2016). Examining the effect of emotional intelligence on socio-demographic variable and job stress among retail employees. International AcDidikmic Journal of Shukla $\mathcal{E}$ Srivastava, Cogent Business \& Management, 3(1), 1-8.

Sugiyono. (2017). Metode Penelitian Bisnis, Pendekatan Kuantitatif, Kualitatif, Kombinasi, dan RED. Yogyakarta: Alfabeta.

Vlachoul, E., Dimitrios, D., George, L., Konstantinos, C., George, K., and MiltiDidiks, K. (2016). The Relationship between Burnout Syndrome and Emotional Intelligence in Healthcare Professionals. Health Science Journal, 10(5), 1-9. 
Wiguna, Meilda. (2015). Pengaruh Role Stress, Role Ambiguity, Self-Efficacy, Sensitifitas Etika Profesi, Gaya Kepemimpinan terhadap Kinerja Auditor dengan Emotional Quotient sebagai variabel Moderating. Jurnal Ilmiah Ekonomi dan Bisnis, 11(2), 503-519.

Wiryathi, N., Rasmini, N. K., dan Wirakusuma, G. (2014). Pengaruh Role Stressors pada Burnout Auditor dengan Kecerdasan Emosional sebagai Variabel Pemoderasi. Jurnal Ekonomi Dan Bisnis Udayana, 3(5), 227-244.

Yusuf, L. (2014). Teori dan Metodologi Ilmu Pengetahuan Sosial Budaya Kontemporer. Jakarta: Rajawali Press. 